J. Lake Sci. (湖泊科学), 2011, 23(2): 191-195

http: //www. jlakes. org. E-mail : jlakes@niglas.ac.cn

(c) 2011 by Journal of Lake Sciences

\title{
三峡水库调节典型时段对鄱阳湖湿地水情特征的影响”
}

\author{
汪迎春 $^{1}$, 赖锡军 ${ }^{2 * *}$, , 姜加虎 $^{2}$, 黄 群 $^{2}$ \\ (1: 蚌埠学院应用化学与环境工程系,蚌埠 233000) \\ (2: 中国科学院南京地理与湖泊研究所湖泊与环境国家重点实验室,南京 210008)
}

摘 要: 三峡工程建成运行将改变下游的水文过程, 影响通江湖泊湿地生态系统. 本文选取水文情势变化大且可能对植 被生长产生较大影响的汛末蓄水和汛前腾空两个时段, 运用长江中游江湖耦合水动力模型计算了三峡水库不同调节流 量下湖泊水位变化特征, 并结合湖泊高程和面积关系曲线, 分析了不同增减下泄流量对洲滩湿地淹没出露的影响. 结果 表明,三峡水库汗未蓄水减泄流量 $1000-7653 \mathrm{~m}^{3} / \mathrm{s}$ 可使大湖面 (都昌站) 水位降低 $0.09-1.11 \mathrm{~m}$; 汗前腾空增泄 $1000-$ $6500 \mathrm{~m}^{3} / \mathrm{s}$, 可使水位抬高 $0.15-0.94 \mathrm{~m}$. 水位影响格局呈现北高南低, 在底水位较高的汛前腾空时段增泄引起水位变化范 围较大, 基本覆盖湖泊主要水面.

关键词: 鄱阳湖;三峡水库;水位;洲滩湿地;水动力学模型

\section{Effect of the Three Gorge Reservoir on the water regime of the Lake Poyang wetlands during typical water-regulation period}

\author{
WANG Yingchun ${ }^{1}$, LAI Xijun ${ }^{2}$, JIANG Jiahu² \& HUANG Qun ${ }^{2}$ \\ ( 1 :Dept. of Chemistry and Environmental Engineering, Bengbu College, Bengbu 233000, P. R. China) \\ ( 2 : State Key Laboratory of Lake Science and Environment, Nanjing Institute of Geography \& Limnology, CAS, Nanjing 210008, \\ P. R. China)
}

\begin{abstract}
Operation of the Three Gorge Project will change the hydrological processes and affect the ecosystem of lake wetland. The two time periods,i. e. water storage after flood season and water emptying before flood season, with highly changed water regime are selected to evaluate the effects of the Three Gorge Reservoir regulation by using the hydrodynamic method. The lake water levels and discharge variations are computed under the different regulation of discharge values. Combined with lake level variations and the elevation-area curve, the wetland exposure area are also analyzed. Results show that lake level of the Lake Poyang (at Duchang Station) would decrease 0.09$1.11 \mathrm{~m}$ for steady flow condition if the discharge of Yangtze river decreases $1000-7653 \mathrm{~m}^{3} / \mathrm{s}$ after flood season, whereas lake level will increase $0.15-0.94 \mathrm{~m}$ if the discharge increases $1000-6500 \mathrm{~m}^{3} / \mathrm{s}$ before flood season. The effect of Three Gorge Reservoir on lake levels varies significantly from northern to southern part of the lake, which are depended on the hydrodynamic connectivity conditions.
\end{abstract}

Keywords: Lake Poyang; Three Gorge Reservoir; water regime; wetland; hydrodynamic model

鄱阳湖是我国第一大淡水湖泊,也是与长江直接相连通的第一大湖.三峡工程建成后, 下游水文情势的 变化将影响到鄱阳湖湿地的水文过程, 对湖泊湿地生态系统的结构与功能会造成一定程度的影响 ${ }^{[1]}$. 有关 三峡对鄱阳湖影响的研究已有不少论文发表, 涉及三峡对防洪 ${ }^{[2-3]}$ 、水文 ${ }^{[4]}$ 、泥沙淤积 ${ }^{[5]}$ 、水环境 ${ }^{[6-7]}$ 和湿地 生态 ${ }^{[8-10]}$ 等. 相关定量研究中采用的方法有:基于水量平衡的大湖演算模型 ${ }^{[3]}$ 、相关分析法或与水动力学结 合 ${ }^{[4]}$ 和神经网络模型 ${ }^{[6]}$ 等. 这些方法一般只能分析某固定点位,如湖口站水位对三峡增减下泄流量的响应, 而不能获取水位变化的空间分布特征. 此外,由于受研究方法理论基础所限,这些不是基于水流物理过程建 立的模型, 不能充分反映鄱阳湖江、河、湖之间复杂水动力相互作用下的水位响应特征, 应用存在局限性. 本

* 中国科学院知识创新工程重大项目 (KZCX1 - YW - 08-01) 和国家自然科学基金项目 (50709034) 联合资助. 2010 04-12 收稿;2010-07-07 收修改稿. 汪迎春, 男, 1976 年生, 博士.

** 通讯作者; E-mail:xjlai@ niglas.ac. cn. 


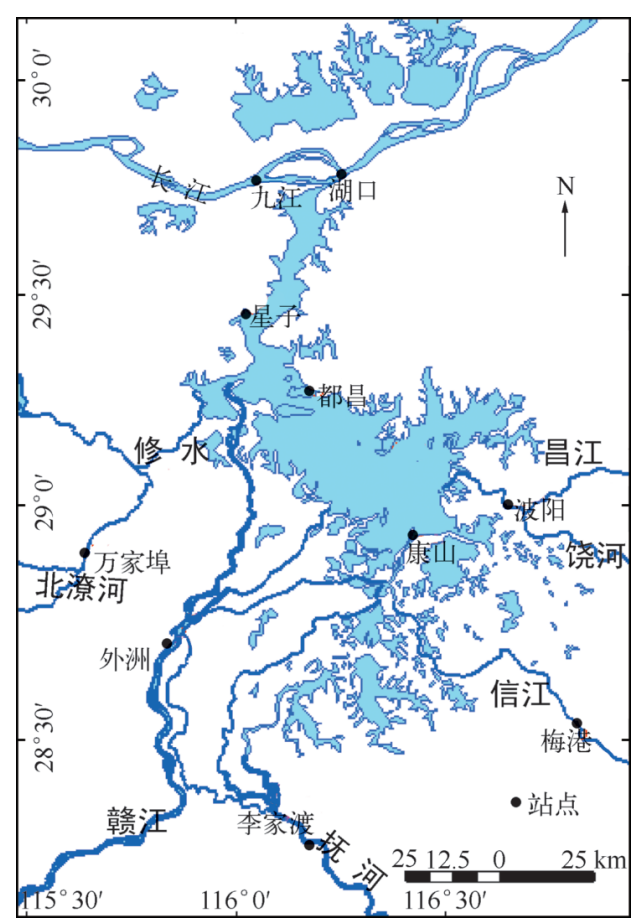

图 1 鄱阳湖水系

Fig. 1 Water system of Lake Poyang and the Yangtze River

文选取水文情势变化大且可能对植被生长产生重大影响 的汛末蓄水和汛前腾空两个典型时段, 运用水动力学模 型方法, 借助于较高分辨率的鄱阳湖计算网格, 完全基于 水动力学方法计算了三峡水库不同调节流量下湖泊水位 的变化特征, 并结合近期湖泊高程和面积关系曲线, 分析 了不同增减下泄流量对洲滩湿地淹没出露的影响.

\section{1 区域概况}

鄱阳湖承纳赣江、抚河、信江、饶河、修水五河来水,经 调蓄后由湖口北注长江, 形成完整的鄱阳湖水系 (图 1), 流域面积为 $16.2 \times 10^{4} \mathrm{~km}^{2}$ (湖泊流域数据引自《中国湖泊 志 $\rangle^{[11]}$,下同). 鄱阳湖由湖口注人长江的多年平均水量为 $1436 \times 10^{8} \mathrm{~m}^{3}$, 鄱阳湖多年平均汇人长江的水量占长江干 流多年平均径流量 (长江大通水文站) 的 $15.6 \%$. 鄱阳湖 区属亚热带湿润季风区，气候温和、降雨充沛、日照充足. 受区域气候以及江、河、湖的交互作用的影响, 鄱阳湖湖水 呈季节性涨落, 具有 “洪水一片、枯水一线” 的独特自然地 理景观. 汛期流域“五河” 洪水人湖和长江来水的顶托, 湖 水漫滩呈 “湖相”, 在湖口水位 $21.69 \mathrm{~m}$ 时, 湖泊水面面积为 $2933 \mathrm{~km}^{2}$. 枯季湖水归槽, 滩地出露, 呈 “河相”. 在多年平均 低水位 $10.20 \mathrm{~m}$ 时,水面面积仅为 $146.0 \mathrm{~km}^{2}$, 出露的洲滩湿 地面积达 $2787 \mathrm{~km}^{2}$. 鄱阳湖独特水文情势和特殊的地理条 件, 繁衍了极其丰富的生物多样性, 蕴藏着珍贵的物种基 因, 是我国陆地淡水生态系统中的重要物种基因库. 鄱阳湖 独特的湿地生态系统使其成为我国公布的首批国家重点湿地之一, 并于 1992 年被列入《世界重要湿地名录》.

\section{2 研究方法与计算方案}

\section{1 水情影响计算方法}

2.1 .1 水动力学模型 本文研究采用江湖耦合水动力学模型方法 ${ }^{[12]}$. 模型由一维河网模型和二维水动力学 模型等模块构成. 模型主要涵盖了宜昌至大通段长江中游主要江河湖水系, 包括鄱阳湖和洞庭湖两个大型 通江湖泊, 长江干流宜昌至螺山段, 湘江湘潭至湖区、资水桃江至湖区、沅水桃源至湖区、澧水津市至湖区等 四水河尾问和三口分流河道, 汉江仙桃至汉口段以及鄱阳湖五河和长江各主要支流清江、沮漳河、东荆河、 府河、滠水、倒水、巴河、浠水、蒴水、晥河等的人流. 为了能够较准确地模拟鄱阳湖地形, 采用的鄱阳湖二维 网格单元共 9630 个, 可以分辨鄱阳湖内部的主要洪道. 模型的下游边界为大通, 给定多年水位一流量关系曲 线. 因此, 在运用模型计算时, 只需给定上游宜昌、洞庭湖四水、鄱阳湖五河各直接汇人长江的支流来流量即 可准确地计算整个区域内部的水位、流量 (湖泊内部为流速) 时空变化过程.

2.1 .2 计算时段选择 根据三峡水库的调度运行方式, 对通江湖泊湿地生态产生重要影响的时段主要发生 在汛末水库蓄水期和汛前腾空库容期. 汛末蓄水和汛前腾空不仅对长江中游水文情势有非常明显的影响, 而且在此期间, 湖泊湿地生态, 特别是植被对水文过程变化非常敏感. 植被春季萌发, 其中优势植被苔草群 落 4-5 月为花盛期,秋季退水会再次萌发, 11 月份开花. 本文将重点计算和分析该两个时段三峡工程运行 对湖泊湿地水情的影响. 在分析三峡蓄水运行对水情的总体影响时, 选取 5 月和 10 月,鄱阳湖五河自身流域 来水正常条件下三峡水库调节增减下泄流量对鄱阳湖湿地水文情势的影响.

2.1 .3 方案设定 三峡工程对鄱阳湖水文情势的影响是动态的过程, 即使在三峡下泄量改变相同的情况下, 不同年份、不同季节、不同时刻鄱阳湖湿地的水情变化也是不一样的. 为使结果能够从平均特性去比较, 考 
察三峡对水情影响的总体特征. 本节运用水动力模型分别计算了在三峡不同增减下泄流量条件下,5 月和 10 月两个代表时段的水文情势变化. 计算条件为: (1) 初始条件:宜昌、鄱阳湖五河当月多年平均来流量驱 动下的恒定流. (2) 边界条件:下游大通控制边界取用多年资料拟合的大通站水位流量关系曲线; 鄱阳湖五 河和主要的支流来水选用当月的平均流量; 宜昌流量边界取三峡下泄流量. (3) 模型参数:选用经由 2006 年 枯水和 1998 年洪水过程验证的参数. (4) 计算共分两组. 在研究时段内增减流量依据三峡调节能力确定. 一 组为 5 月份增泄影响计算, 三峡下泄流量在平均来流量基础上分别增加 $500 、 1000 、 1500 、 2000 、 2500 、 3000 、$ $3500 、 4000 、 4500 、 5000 、 5500 、 6500 \mathrm{~m}^{3} / \mathrm{s}$ 共 12 种方案. 另一组为 10 月份减泄影响计算, 三峡下泄流量在平均 来流量基础上分别减少 $500 、 1000 、 1500 、 2000 、 2500 、 3000 、 3500 、 4000 、 4500 、 5000 、 5500 、 6000 、 7653 \mathrm{~m}^{3} / \mathrm{s}$ (下泄 量为 $10000 \mathrm{~m}^{3} / \mathrm{s}$ ) 共 13 种方案.

2.1 .4 恒定流水位的代表性 根据上游平均来流量 计算得到的恒定流水位与鄱阳湖各站多年平均水位 (1960-2007 年)基本吻合,能够反映研究时段的水 位总体特征 (表 1 ). 需要指出的是, 湖泊水位是一个 动态变化的过程,多年平均水位不可能与多年平均 来流驱动下的恒定流水位相同. 用这一数据对比是 为了说明基于恒定流条件计算的代表性,而不是对 模型进行验证.

\section{2 湿地淹没面积计算方法}

根据实测的湖泊水下地形图建立鄱阳湖的 DEM, 计算得出鄱阳湖的高程 (黄海基面) - 面积曲 线关系 (图 2). 在此基础上,计算三峡水库不同调节 流量下水位对应的鄱阳湖湿地水面面积,评估三峡 蓄水运行对鄱阳湖湿地淹没和出露状况. 基于高程面积曲线关系评估三峡工程对湖泊湿地洲滩出露淹 没的影响, 需确定湖泊特征水位. 鄱阳湖为吞吐型湖 泊,在研究的 5、10 月份湖水面可能存在较大的坡 降,水位沿程递减. 为此, 鄱阳湖特征水位取湖泊由 北向南的星子、都昌和康山三站水位平均值.

\section{3 结果与分析}

\section{1 水库汛末蓄水时段的影响}

对三峡水库汛末蓄水期间减泄的影响,按 10 月平均来流量条件进行计算. 当三峡下泄流量减少 1000 、 $2500 、 3500 、 7653 \mathrm{~m}^{3} / \mathrm{s}$ 时, 湖口水位分别降低 $0.11 、 0.47 、 0.58 、 1.55 \mathrm{~m}$; 都昌站分别下降 $0.09 、 0.38 、 0.49$ 、 $1.11 \mathrm{~m}$; 康山变化很小 (图 3a). 长江流量减泄对鄱阳湖的影响从北部湖口至南部的康山逐级递减,水位减幅
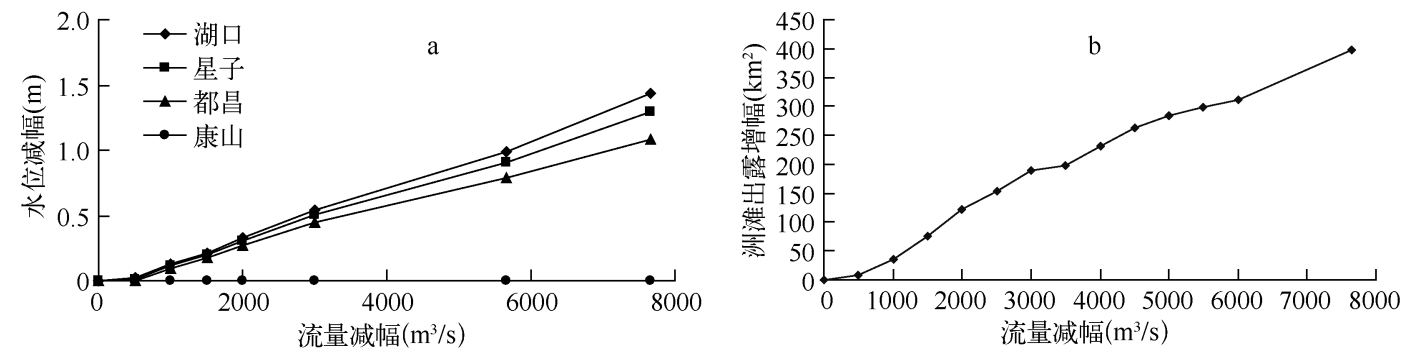

图 3 三峡汛末蓄水减泄流量对鄱阳湖水位 $(\mathrm{a})$ 和洲滩出露 $(\mathrm{b})$ 的影响

Fig. 3 Stage reduction(a) and grassland area increase(b) corresponding to the reduction of Three Gorge Reservoir discharge during water storage period after flood season 
呈现北高南低的空间格局 (图 4). 鄱阳湖洲滩在 10 月份已开始显露, 北部湖区的湖口水道和北部大湖面因 水力连通性较好, 水位变幅受长江影响较大. 蛙湖等洼地和南部湖区因水力连通性差, 水位变化所受影响 较小.
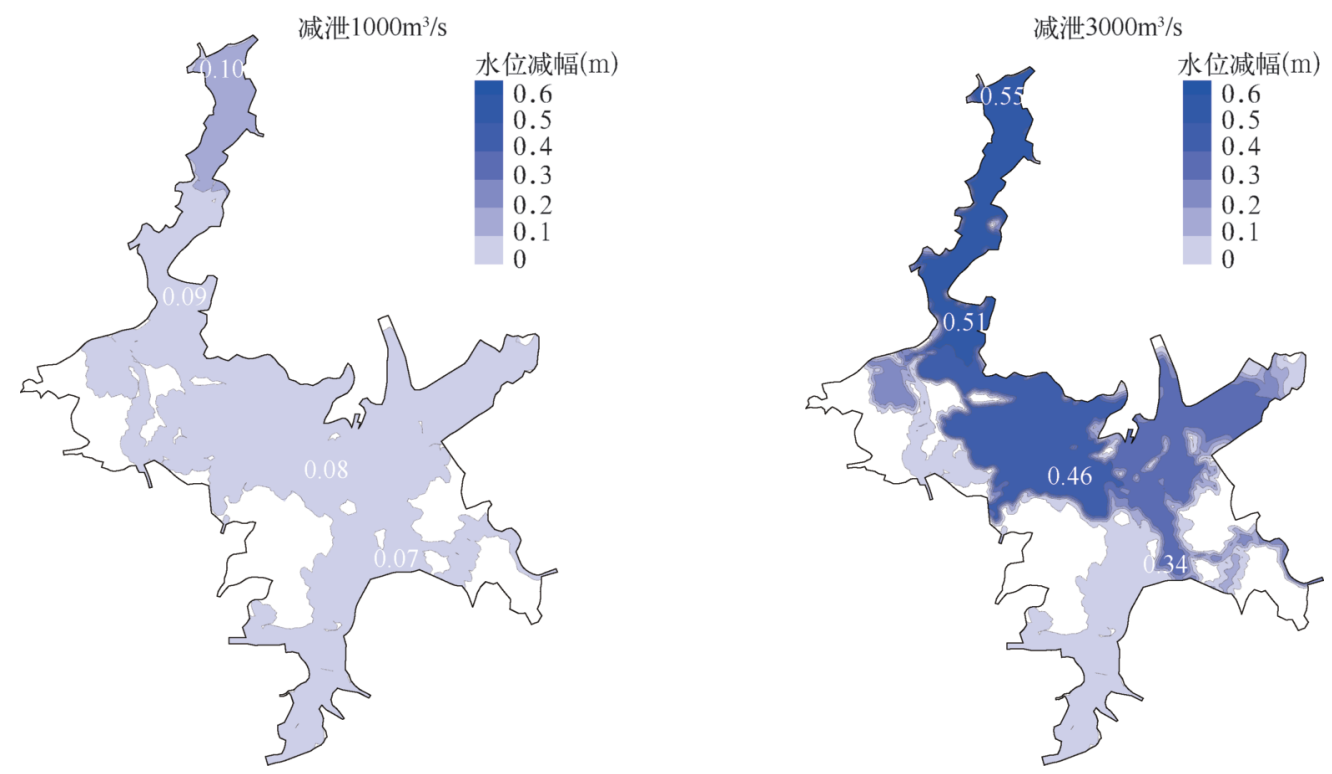

图 4 三峡汛末蓄水不同减泄流量下水位减幅的空间分布

Fig. 4 Spatial pattern of stage reduction under different conditions during water storage period after flood season

对汛末蓄水的情景, 当三峡下泄流量减少 $1000 、 2500 、 3500 、 7653 \mathrm{~m}^{3} / \mathrm{s}$ 时, 鄱阳湖洲滩出露面积将分别增 加 $35.0 、 154.2 、 197.2 、 397.9 \mathrm{~km}^{2}$, 洲滩出露面积随流量减少 (图 3b), 在减泄量较小时, 洲滩面积变化较快. 但是在 $3000 \mathrm{~m}^{3} / \mathrm{s}$ 之后, 水流归槽, 洲滩面积变化趋缓.

\section{2 水库汛前腾空时段的影响}

三峡水库腾空库容期间, 当三峡下泄流量增加 $1000 、 2500 、 3500 、 6500 \mathrm{~m}^{3} / \mathrm{s}$ 时, 湖口水位分别增加 0.22 、 $0.51 、 0.70 、 1.28 \mathrm{~m}$; 都昌站的水位分别增加 $0.15 、 0.36 、 0.50 、 0.94 \mathrm{~m}$ (图 $5 \mathrm{a}$ ). 与汛末蓄水时段水位影响的格 局大体一致,水位变化北部湖区大于南部湖区 (图 6). 不过, 由于 5 月份鄱阳湖五河处于汛期,南部湖区底水 位较高, 水力连通性较好, 此时, 三峡增泄的影响范围较汛末蓄水时段要大, 南部湖区康山站的水位也随着 三峡下泄量的增加而抬升.
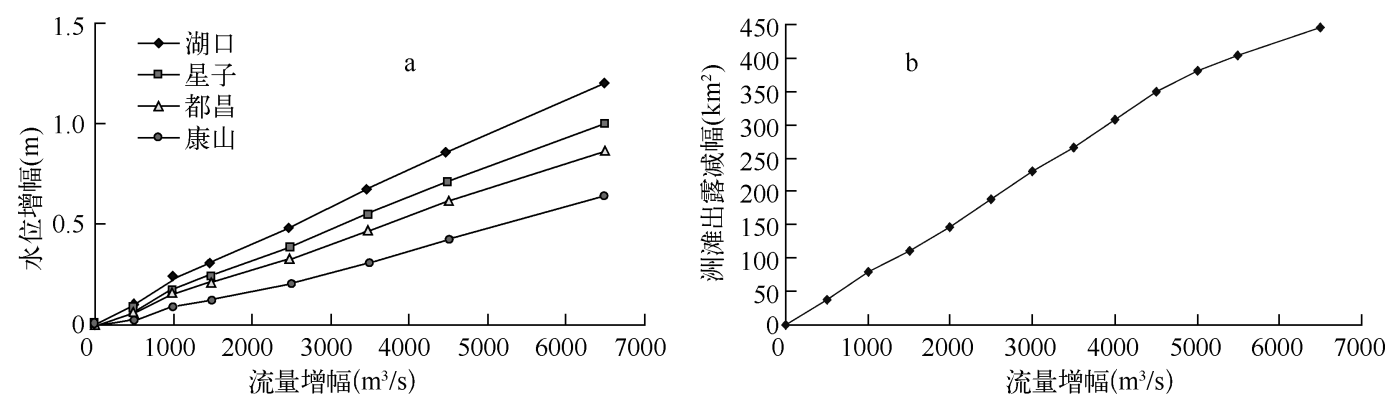

图 5 三峡汛前腾空增泄流量对鄱阳湖水位 (a) 和洲滩出露 (b) 的影响

Fig. 5 Stage increase(a) and grassland area reduction(b) corresponding to the increase of Three Gorge Reservoir discharge during water storage period before flood season 

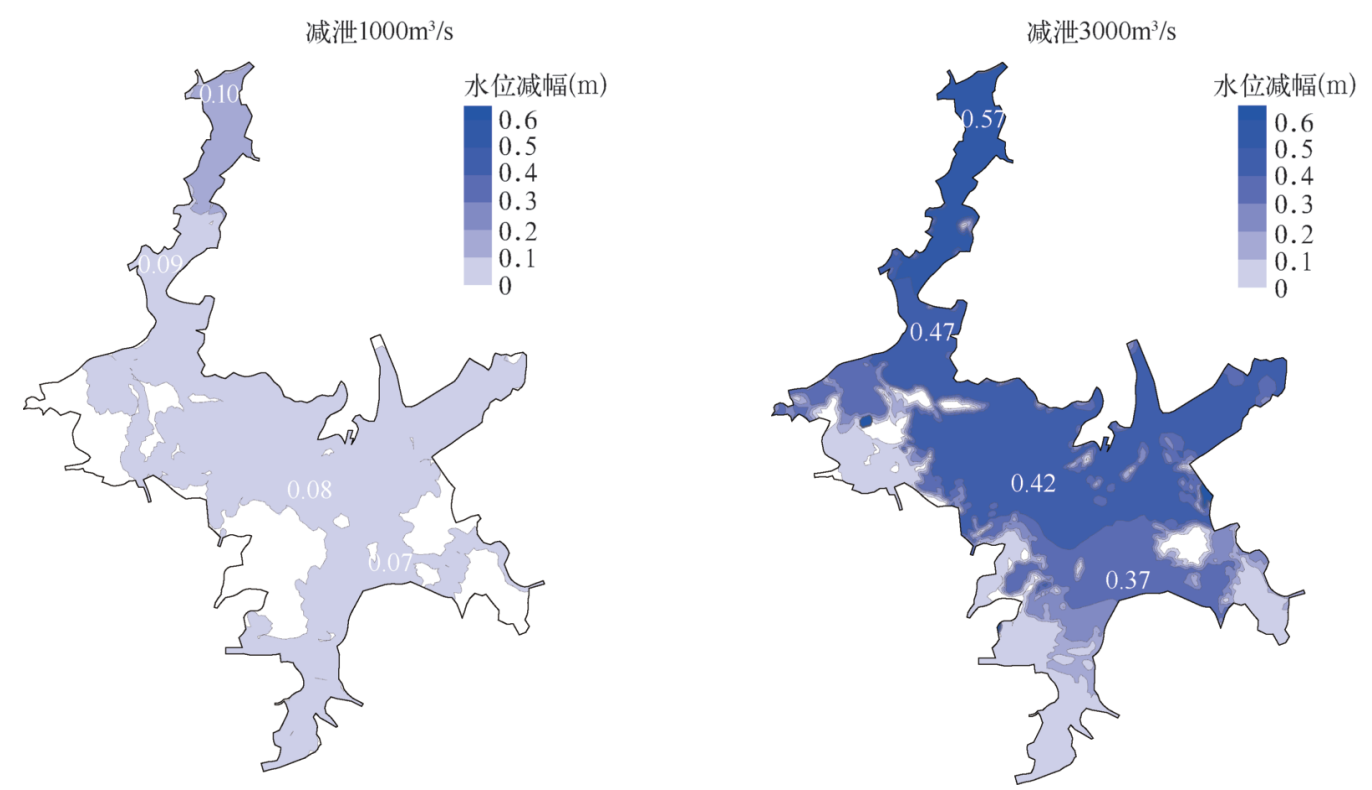

图 6 三峡汛前腾空不同增泄流量下水位增幅的空间分布

Fig. 6 Spatial pattern of stage reduction under different conditions during water storage period before flood season

对汛前腾空的情景 ( 5 月份), 当三峡下泄流量增加 $1000 、 2500 、 3500 、 6500 \mathrm{~m}^{3} / \mathrm{s}$ 时,洲滩出露面积分别降 低 79.2、188.5、266.6、445. $0 \mathrm{~km}^{2}$ (图 5b). 在增泄初期基本呈线性增长, 当增泄至 $6000 \mathrm{~m}^{3} / \mathrm{s}$ 之后, 洲滩基本 已被淹没,淹没面积趋于稳定.

\section{4 结语}

本文选取汛末蓄水和汛前腾空两个对湿地植被影响较大且三峡调节作用明显的典型时段, 采用江湖耦 合水动力学模型计算了恒定流条件下三峡水库不同调节流量下鄱阳湖水位,分析了鄱阳湖水位受三峡水库 调节的影响大小以及空间格局特征. 并以高程一面积曲线分析这两个时段调节对鄱阳湖洲滩面积的影响,初 步掌握了三峡汛末蓄水和汛前腾空期对湿地水情总体特征的影响.

\section{5 参考文献}

[ 1 ] 兴培民,蔡述明. 三峡工程与长江中游湖泊洼地环境. 北京:科学出版社, 1994:196-199.

[2] 傅 春,刘文标. 三峡工程对长江中下游鄱阳湖区防洪态势的影响分析. 中国防汛抗旱,2007,(3):18-21.

[ 3 ] 胡细英,朱宏富. 三峡工程与鄱阳湖区重要城市防洪. 江西师范大学学报: 自然科学版, 1998,22(4) :365-370.

[ 4 ] 姜加虎,黄 群.三峡工程对鄱阳湖水位影响研究. 自然资源学报,1997,12(3):219-224.

[ 5 ] 王云飞. 三峡工程对鄱阳湖冲淤的影响和预测. 湖泊科学, 1994,6(2) :124-130.

[6] 朱信华,董增川,赵 杰等.三峡工程对鄱阳湖水质的影响. 人民黄河,2009,(1):57-58.

[ 7 ] 郑 林. 三峡工程对鄱阳湖水环境质量影响的初步分析. 江西师范大学学报: 自然科学版,1998,22(2):177-180.

[8] 吴龙华. 长江三峡工程对鄱阳湖生态环境的影响研究. 水利学报,2007,(S1):586-591.

[ 9 ] 刘 影,徐 燕. 三峡工程对鄱阳湖候鸟保护区的影响及对策探讨. 江西师范大学学报: 自然科学版, 1994,18(4): 375-380.

[10］吕兰军,王仕刚.三峡工程对鄱阳湖珍稀候鸟越冬栖息地水位影响分析. 人民长江,1991,22(7):38-43.

[11］王苏民,窦鸿身. 中国湖泊志. 北京:科学出版社,1998: 218-219.

[12] Lai X. Coupled hydrodynamic model for the middle Yangtze River basin with complex lake-river interaction. Journal of Hydrology ( submitted). 